\title{
AC 2010-1792: PREFERENCES AND CHALLENGES FOR FEMALE GRADUATE ENGINEERING STUDENTS: A SURVEY BASED STUDY
}

\section{Soumya Srivastava, Mississippi State University}

Soumya K. Srivastava is a PhD student in Chemical Engineering at Mississippi State University since August 2007. She received her M.S from Illinois Institute of Technology, Chicago and B.S from R.V. College of Engineering, Bangalore, India. She has worked as an intern research engineer at Bayer Biologicals, co-op chemist at American Air Liquide, Chicago during her MS degree. Before joining MSU she was at Warren Analytical, Greeley, CO for 1.5 years as a Research Associate Chemist. Her research involves building lab-on-a-chip device for medical diagnostic applications. She recently was voted to be the Graduate Ambassador for Chemical Engineering Department at MSU and also has won an award for maximum number of publications in a year. She is associated with Medical microDevice Engineering Laboratory (M.D.-ERL) at MSU working under Dr. Adrienne Minerick. Soumya is an active member of AIChE, AES, ASEE, SWE and Sigma-Xi.

\section{Anurag Srivastava, Mississippi State University}

Anurag K. Srivastava received his Ph.D. degree from Illinois Institute of Technology (IIT), Chicago, in 2005, M. Tech. from Institute of Technology, India in 1999 and B. Tech. in Electrical Engineering from Harcourt Butler Technological Institute, India in 1997. He is working as Assistant Research Professor at Mississippi State University since September 2005. Before that, he worked as research assistant and teaching assistant at IIT, Chicago, USA and as Senior Research Associate at Electrical Engineering Department at the Indian Institute of Technology, Kanpur, India as well as Research Fellow at Asian Institute of Technology, Bangkok, Thailand. His research interest includes engineering education and power system. Dr. Srivastava is member of ASEE, IEEE, IET, Power and Energy Society, Sigma Xi and Eta Kappa Nu. He is recipient of several awards and serves as reviewer for numerous international journals and conferences.

\section{Adrienne Minerick, Mississippi State University}

Adrienne R. Minerick is an Associate Professor of Chemical Engineering at Michigan Technological University (MTU). From July 2003 through December 2009, she was on the faculty of the chemical engineering department at Mississippi State University (MSU). She received her PhD and M.S. from the University of Notre Dame and B.S. from Michigan Technological University. At MSU, Dr. Minerick taught the graduate Chemical Engineering Math, Process Controls, Introduction to Chemical Engineering Freshman Seminar, Heat Transfer, and Analytical Microdevice Technology courses. In addition, she is an NSF CAREER Awardee, has served as co-PI on an NSF REU site, PI on grants from NSF and DOE, and is the faculty advisor for MSU's chapter of the National Organization for the Professional Advancement of Black Chemists and Chemical Engineers (NOBCChE). Her research is in medical microdevice diagnostics \& Dielectrophoresis.

\section{Noel Schulz, Mississippi State University}

Noel N. Schulz received her B.S.E.E. and M.S.E.E. degrees from Virginia Polytechnic Institute and State University in 1988 and 1990, respectively. She received her Ph.D. in EE from the University of Minnesota in 1995. From July 2001 through August 2009, she was on the faculty of the ECE department at Mississippi State University as the TVA Professor of Power Systems Engineering. She is Paslay Professor in the ECE Department at Kansas State University since August 2009. Noel serves on the ASEE Board of Directors as the PIC IV Chair from 2008-2010. She has also been active in the IEEE Power \& Energy Society and served as Secretary for 2004-2007 and Treasurer for 2008-2009. 


\title{
Preferences and challenges for female graduate engineering students: A survey based study
}

\begin{abstract}
Increasing the number of female graduate students in engineering education has always been challenging. This study presented here examines the preferences and self-recognized challenges identified by international female graduate engineering students at U.S. schools. These findings can also be used by institutions to attract more female students in graduate engineering programs by integrating in ongoing recruitment and retention efforts. Research findings are based on a comprehensive online survey designed and conducted by the authors, who are of diverse nationality, educational background, and gender. Male and female international graduate students and alumni at U.S. schools were invited to complete the online survey. Results indicate that preferences of international students to choose a graduate school differ by gender and female students tend to choose a school on a different set of criteria compared to their male colleagues. Common challenges faced and preferences adopted in choosing a school identified by female graduate students are compiled, contrasted to male responses, and presented. Survey results discussed here can be directly applied by institutions to improve recruiting and retention of women graduate engineering students.
\end{abstract}

\section{Introduction}

Importance of recruiting and retention of engineering students to keep up with workforce demand and technological advancements have been highlighted in several publications ${ }^{1-4}$ in the past. Institutions of higher learning are under tremendous pressure to improve recruitment to keep up with educational competence and better student outcomes such as retention and completion $^{2}$. There are several factors that contribute towards increasing recruitment and retention including engineering image ${ }^{3}$, institutional administrators, faculty members and students themselves ${ }^{4}$. Understanding the diversity of engineering students and incorporating that in recruiting and retention efforts are very important to maintain diversity ${ }^{5}$. Evaluating challenges and preferences of female students and integrating in recruitment efforts will definitely help the institutions. Cultural and gender diversity among students in academic institutions and among employees in the corporate world brings different perspectives to the academic and corporate environment and substantially helps with the growth. Engineering students could be distinguished based on gender, nationality, regions, ethnicity and age group. International students play a major role in increasing the diversity of graduate engineering students and contribute in many ways ${ }^{6}$. Understanding challenges faced by international and minority students is critical for a successful graduate program ${ }^{7-9}$. Najafi et al. presented a typical global model to increase the enrollment of minority and international graduate students ${ }^{10}$.

Women are significantly underrepresented among engineering student population and have been a minority for several decades ${ }^{11}$. Several studies in the past have examined the lower number of female students in engineering and have discussed strategies to recruit and retain women students in science and engineering ${ }^{11-14}$. Globally, female professional scientists represent $25-35 \%$ of the research workforce ${ }^{15}$. As of 2006 data, approximately $20 \%$ of engineering students are female ${ }^{16}$. One theory regarding why females are represented in lower numbers, is a cultural influence that discourages participation in engineering area ${ }^{16}$. Some of the suggested solutions are providing tools and methods to female students for early exposure to 
technology, confidence in using technology, information to enhance technological literacy, willingness to learn new skills, and higher levels of trust in technology ${ }^{17}$. One of the studies aimed at determining a more accurate measure of retention, examining the factors affecting retention of females, and increasing the retention rates as conducted by Brainard et al. ${ }^{18}$. Authors reported that the freshmen and sophomore years are the times when women students are most likely to switch out of an engineering program.

In another study, first-year and final-year female undergraduates in a male-dominated academic area reported higher levels of discrimination and stereotype threat than women in a female-dominated academic area ${ }^{19}$. Survey results based on 437 sixth grade students showed that there continues to be significant gender difference in science experiences, attitudes, and perceptions of science courses and careers ${ }^{20}$. Girls generally tend to choose professions that help humanity and they need to be shown how engineering principles, such as biomedical engineering, can be applied to improve human life ${ }^{21}$. Use of integrative multimedia courseware was presented to support and accommodate student learning style differences to improve the retention of underrepresented engineers ${ }^{22}$. Enhanced presence of women into visible and influential academic and engineering positions by improving graduation rates for female graduate students was provided as a solution for improving recruitment and retention of undergraduate female students ${ }^{23}$. Felder et al. observed gender differences in performance and attitudes based on several chemical engineering classes ${ }^{24}$. The unexpected performance of female students in class may be caused by prejudices acquired prior to college, differences in priorities, shortage of female role models, instructional methods and the attitudes of professors, advisors, and classmates as suggested by Felder et al.

In this study, an online survey was conducted to evaluate the preferences, influential factors and common challenges for female students. Results were compiled and interpreted in a way, to also enhance the recruitment and retention of international female graduate students. In the next two sections, survey design and survey findings in detail have been presented and the last section concludes the paper.

\section{Survey Design}

This online survey approved by International Review Board (IRB) at Mississippi State University was designed by a group of faculty members and a student. Respondents were kept confidential and the survey was voluntary, open to only international graduate students at U.S. universities. There were 1180 students and alumni who took the survey from STEM fields at U.S. schools recruited via contacting student organizations, administrative offices and colleagues. Among them, 558 were current students at an U.S. university from an engineering background, with 421 males and 137 females. Students were from different nationality including Africa, Asia, Australia and Pacific Islands, Europe / Russia (but not Scandinavia), Middle East, North America (Canada and Mexico), and South America. The actual number of invited respondents and the response rate was not known, as the respondents were not directly contacted.

Survey data was analyzed using Microsoft Excel software due to ease of analysis and interpretation. In future, more complex statistical analysis will be done using comprehensive commercial tools. Specific questions relevant to this paper are presented and discussed in the survey findings section. Results are presented graphically in column graphs, and radar graphs to better visualize the data. 


\section{Survey Findings}

This section focuses on the common challenges faced, preferences adopted in choosing a school, campus department helpfulness with initial paperwork, experience with faculty members, safety and security of campus identified by female graduate students contrasted to male

responses along with some open ended responses. The survey findings presented here are based only on engineering student population and not alumni students.

\section{Common Concerns for prospective students:}

In this survey conducted online, the students were asked to rank a list of eleven most common concerns with 1 as the greatest concern and 11 as little or no concern. The common concerns were:

1. Transcript evaluation

2. Meeting the deadlines for admission

3. Getting VISA

4. Being accepted into the program

5. Housing

6. Language and culture change

7. Funding/ Support

8. Finding a good academic advisor

9. Finding good courses

10. Finding job after graduation

11. Safety and security of the Campus

\section{Concerns before attending school}

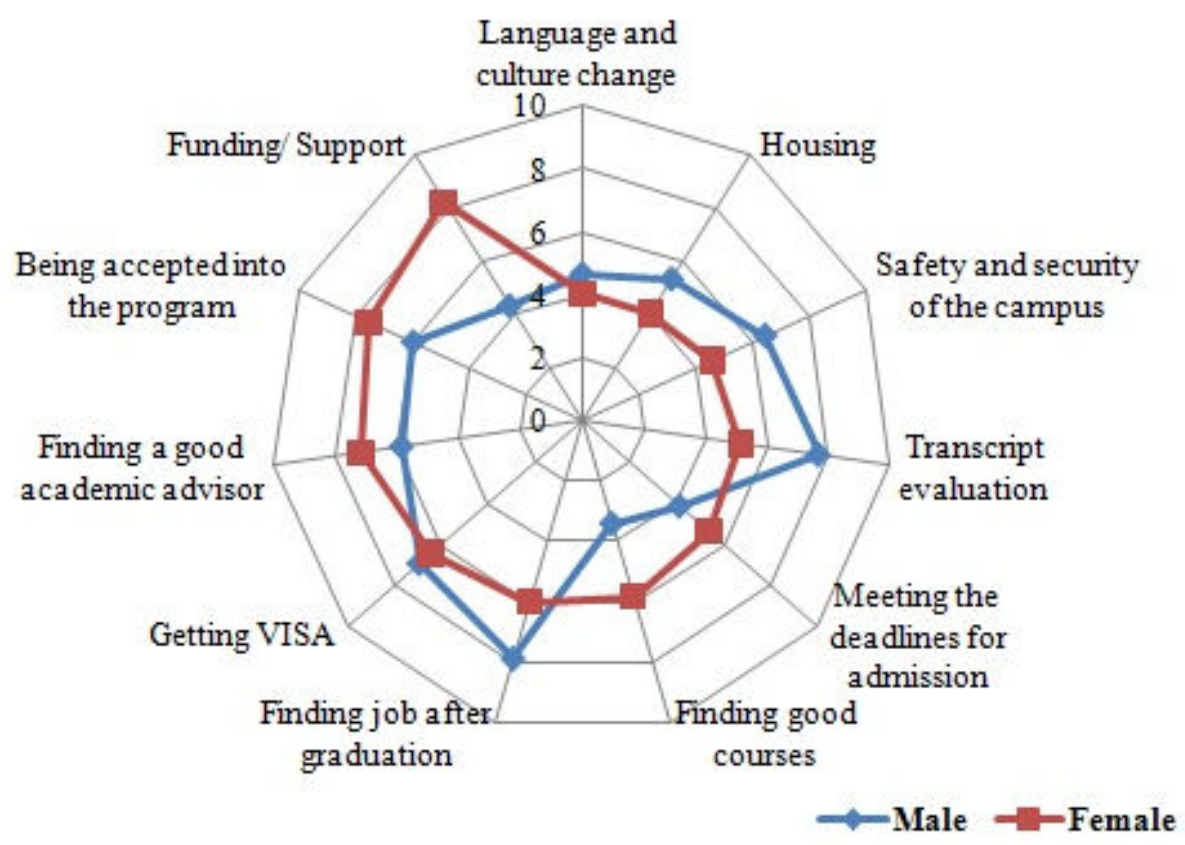

Figure 1: Concerns among prospective students ranked. Male and female responses are contrasted by calculating the average rank for current student's population. Variability among the concerns is seen. 
In this paper, male and female responses are contrasted by calculating average rank based on the ranking provided by the respondents. Significant variability was found between male and female respondents as shown in Figure 1. Top most concern differed between male and female students.

For female students the top 3 concerns were:

1. Funding/Support (composite rank of 8.2)

2. Being accepted into the program (composite rank of 7.5)

3. Finding a good academic advisor (composite rank of 7.2)

For male students, the top 3 concerns were:

1. Finding job after graduation (composite rank of 7.9)

2. Transcript evaluation (composite rank of 7.7)

3. Getting VISA (composite rank of 6.9)

The least ranked concern was "Finding good courses" for male students and for female students it was "Language and culture change" with "Housing".

$\underline{\text { Prospective students' influential factors in choosing a school: }}$

This section of the online survey sought to determine which factors influences the most from the student's perspective to decide on a particular school. Survey respondents were asked to rank the following factors based on which influenced the most in their decision to apply to a particular university with 1 as greatest influence and 10 as little or no influence. Below were the options given to respondents:

1. University recruitment effort

2. Correspondence with graduate school/professors before arrival

3. Funding opportunities

4. Ranking of the school

5. International student population

6. Location of university

7. Quality of faculty members

8. Employment prospects after graduation

9. Overall expenses

10. Having friends or someone you knew

Figure 2, shows the influential factors based on gender of the survey respondents. Male student population, ranked location of the university and university recruitment efforts as the top most influential factors whereas female students ranked funding opportunities and ranking of school as the top 2 influential factors for deciding the school for their graduate studies.

For female students the top 3 influential factors in choosing a school were:

1. Funding opportunities (composite rank of 7.2)

2. Ranking of school (composite rank of 6.7)

3. Quality of faculty members (composite rank of 6.4) 
For male students, the top 3 concerns were:

1. Location of university (composite rank of 6.8)

2. University recruitment effort (composite rank of 6.7)

3. Employment prospects after graduation (composite rank of 6.3)

\section{Influential factors}

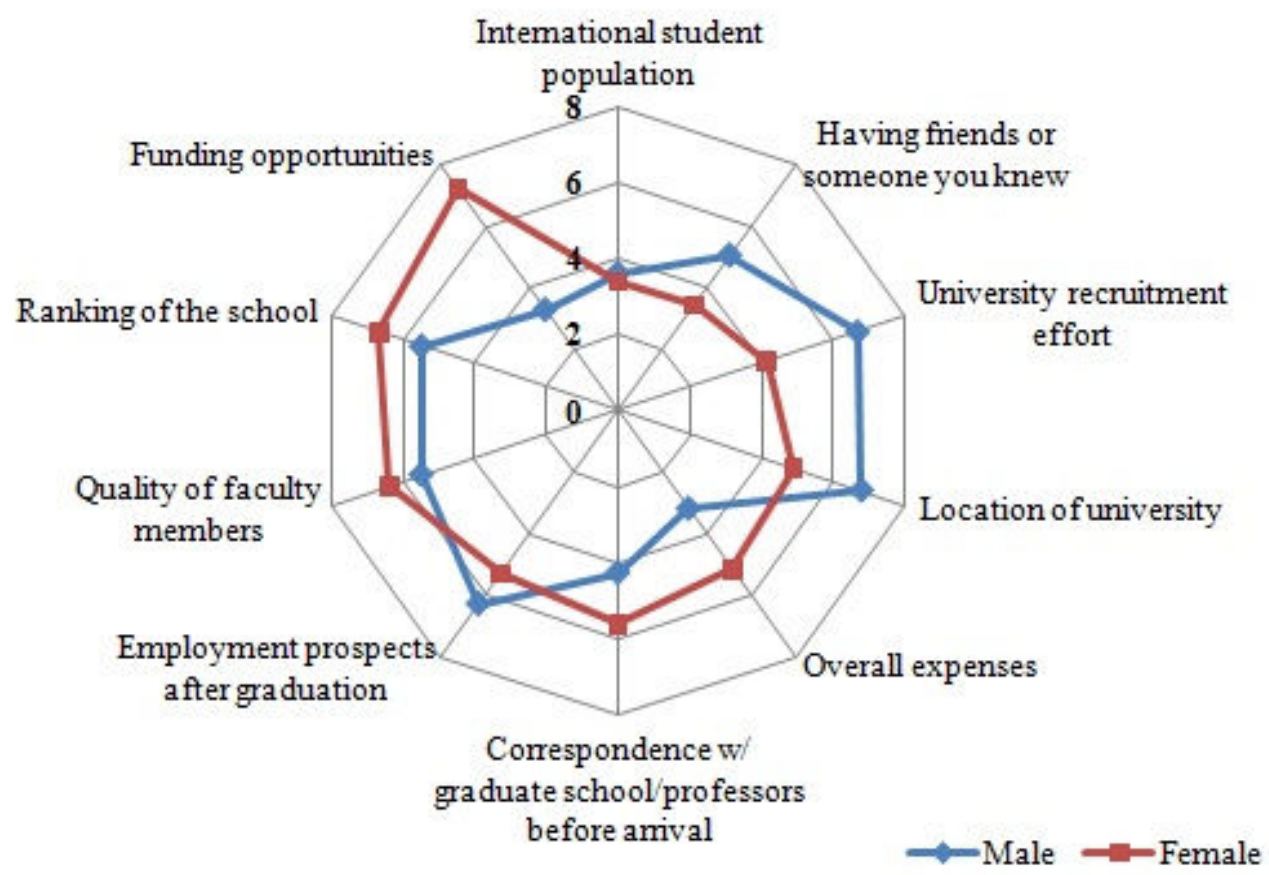

Figure 2: Influential factors for choosing a school. Male and female responses contrasted by calculating average rank. Top influential factor is different for male and female current student populations.

Graduate studies challenges:

In this section, survey respondents were asked to respond the most challenging phase they experienced during their graduate studies. Multiple responses could be selected for this particular question. They were also given the option to add any other challenging factor they experienced during their studies at U.S. universities. There were five different options to be selected from:

1. Admission

2. Getting VISA

3. In school

4. I did not have difficult phase

5. Other (Please specify) 
Figure 3, shows the difficult phases during graduate studies. The most difficult phase for both male and female students was "in school (coursework, funding, adjusting with culture, etc)".

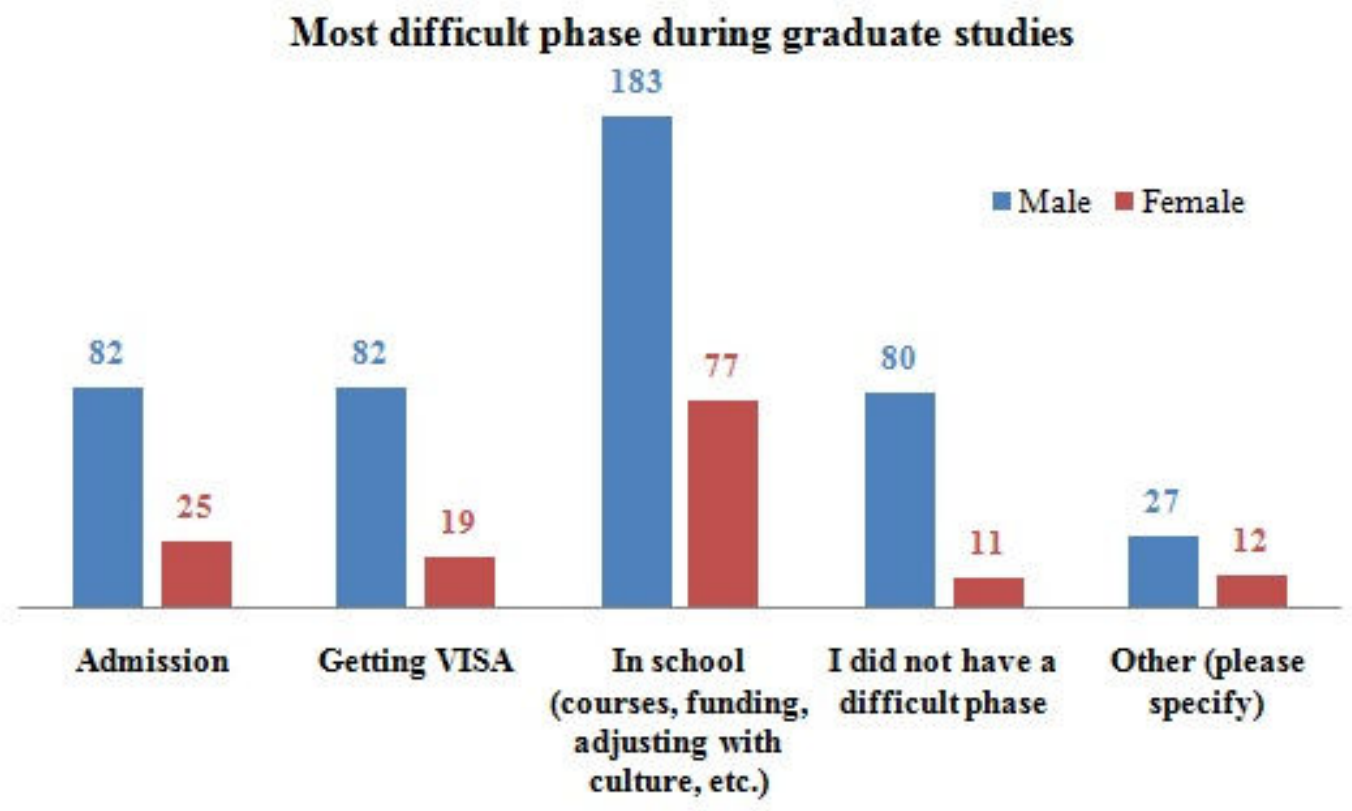

Figure 3: Difficult phases during graduate studies experienced by students. Most difficult phase for both male and female students was "in school".

There were some open ended responses for the option "other (please specify)" provided in the questionnaire.

Some of the female students' responses for this option are listed below:

- Communication skills

- Conducting research

- If you are Iraninan, life is not gonna be as fair for you as the other students from other countries. One simple example: getting single entry visa for seven years (!) and not being able to visit family during the whole time. I wanna study here just like all the other students, and I'm not really interested in politics. But I can't even go to conferences overseas!

- Qualifying exam

- Single entry visa issues

- Finding an interesting project

Graduate school expectations:

This survey questionnaire addresses, if the students expectations were met after joining the graduate school. The options for this question were on a 5-point scale: Exceeded expectations, very good, good, fair and poor. From figure 4, more than $50 \%$ of the respondents felt good about their choice of school. About $6 \%$ of male population thought it was a poor choice, but only about $2 \%$ of female population thought it was poor selection of graduate school. 


\section{Graduate School Expectations}

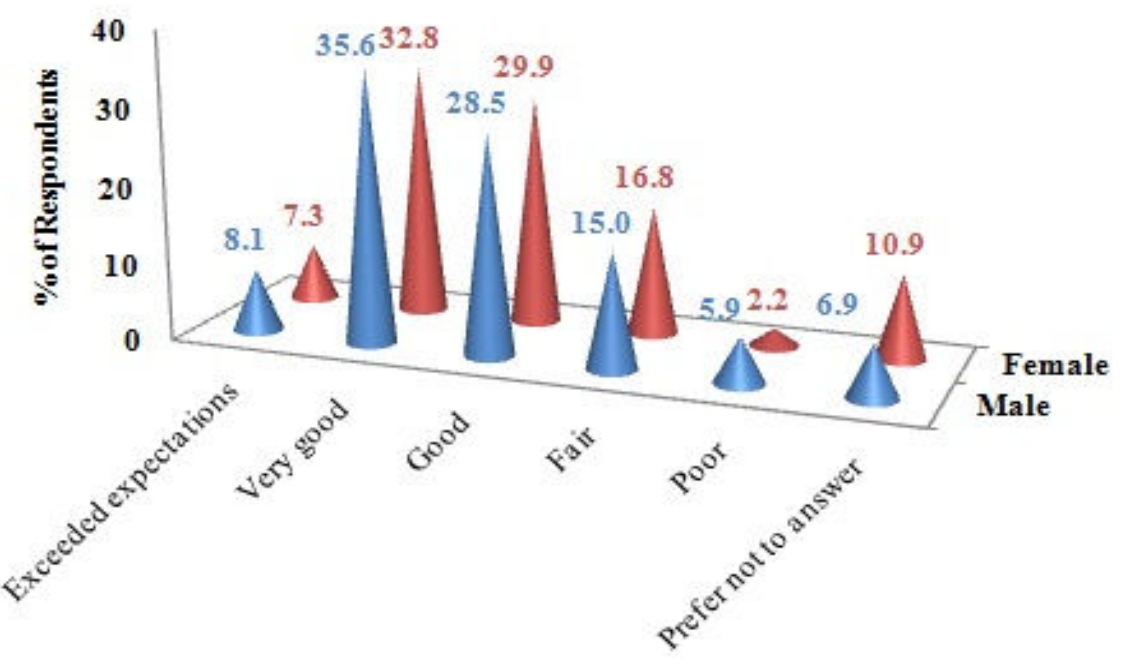

Response Options

Figure 4: Graduate school expectations. Only $~ 8 \%$ of the both male and female student population felt that their choice of the school exceeded expectations.

Safety and Security of campus:

This survey also aimed at inquiring about how satisfied were the students about safety and security of campus. Figure 5 shows that more than $65 \%$ of male and female population were very satisfied with the safety and security provided in the campus where they went to graduate school.

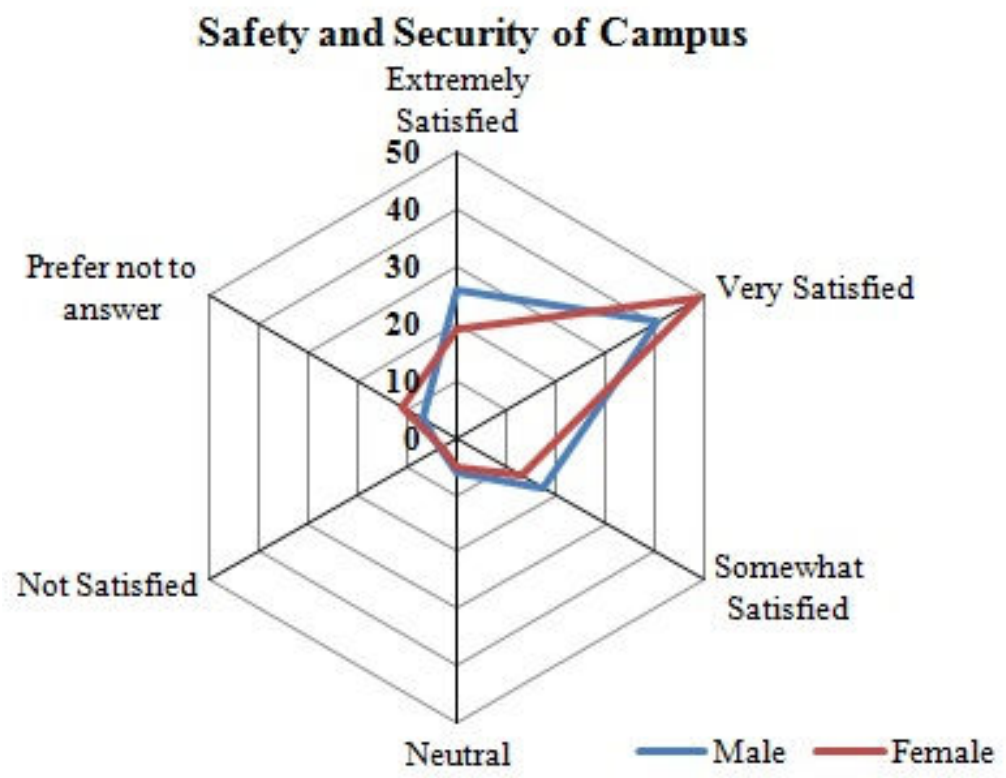

Figure 5: Campus safety and security. Both male and female current students (about 65\%) were very satisfied with the safety and security. About $30 \%$ of both populations were less satisfied or unsatisfied with the safety and security. 
Campus department assistance with initial paper work:

Another important aspect of the survey was to know how helpful the campus departments with student's initial paperwork were. The campus departments considered here were:

1. International students' organization

2. Graduate admission office

3. Students' home department

4. Student health center

5. Housing office

Respondents were given 5 options to choose from: 1) Extremely helpful 2) Helpful 3) Somewhat helpful 4) Neutral 5) Not Helpful for each campus organizations. From figure 6, the overall responses were biased towards helpful or neutral for each organization. Housing office showed very less satisfied people and more neutral response along with student health center. Students' home department had more population of respondents indicating extremely helpful response. Male and female student responded very similarly with slight variation.

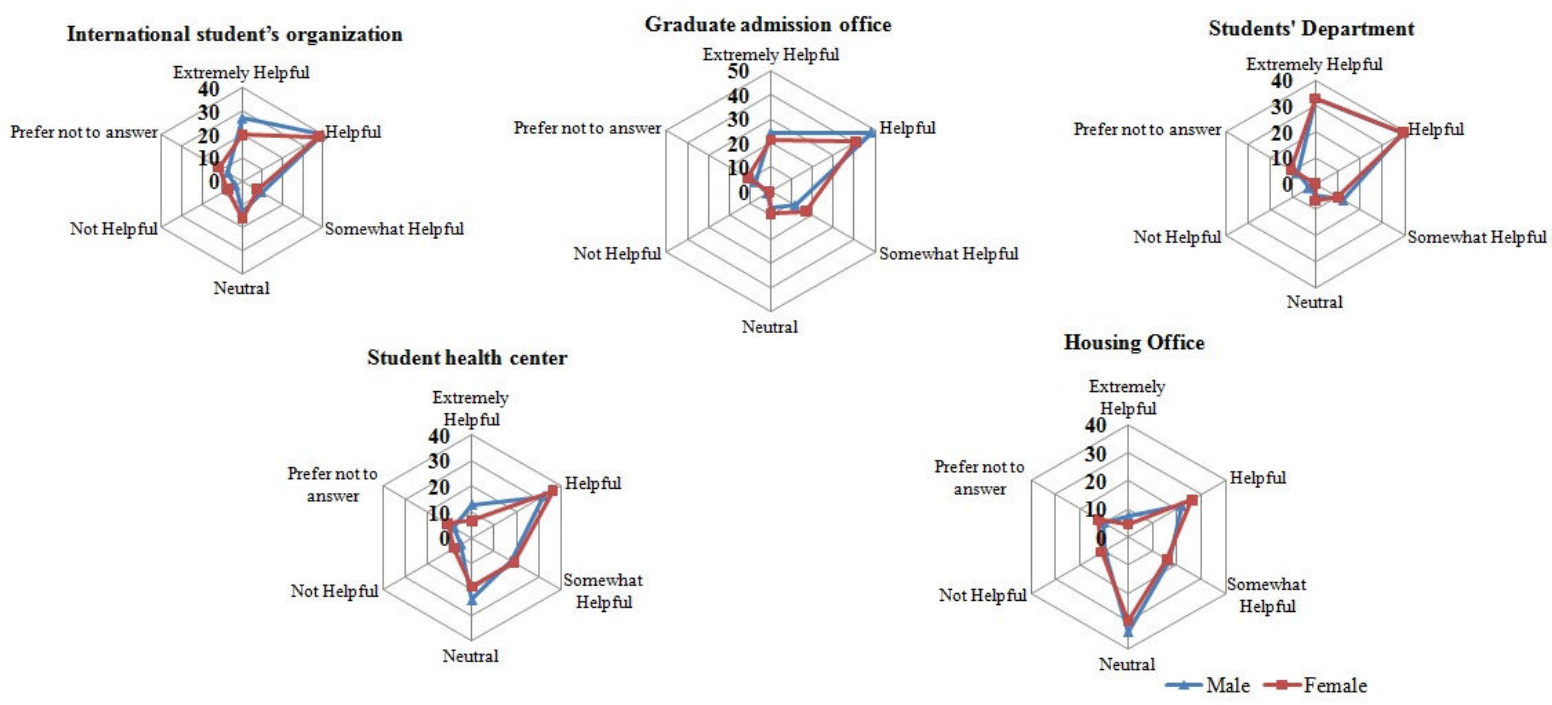

Figure 6: Helpful departments around the campus including both male and female students' responses. Most satisfying and helpful department was the student's home department where more than $30 \%$ of population indicated extremely helpful response.

Experience with faculty members/ advisors:

A section of the survey also included students' perceptions towards their faculty members and advisors. The students were to choose an option from the 5 listed options: including 1) Very Helpful 2) Helpful 3) Neutral 4) Not helpful 5) Too busy to talk with me.

More than $75 \%$ of the current student population including both genders indicated that their faculty members and advisor were helpful. About $5 \%$ of the male student population had negative experience with their advisors and about $1.5 \%$ of the female population ranked the helpfulness of faculty members negatively. 


\section{Experience with faculty members}

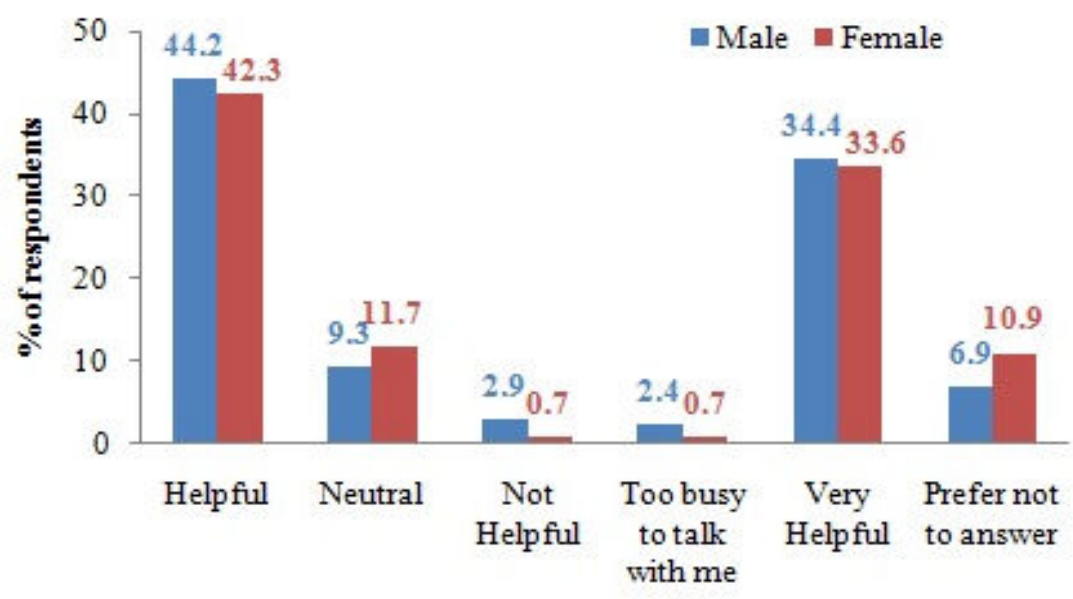

Figure 7: Students' perceptions towards faculty members. More than $75 \%$ of the student population indicated that faculty members were helpful.

Overall education system:

Survey respondents were also asked about their thoughts on the overall education system in U.S. The options were 1) Very easy 2) Easy 3) Neutral 4) Difficult 5) Very Difficult. About $34 \%$ of female students felt the education system in U.S. to be easy and about $24 \%$ thought that education in U.S. was difficult. In contrast, about $47 \%$ of male students felt education in U.S. to be easy and $17 \%$ felt difficult as shown in figure 8 .

\section{Overall Education System in U.S.}

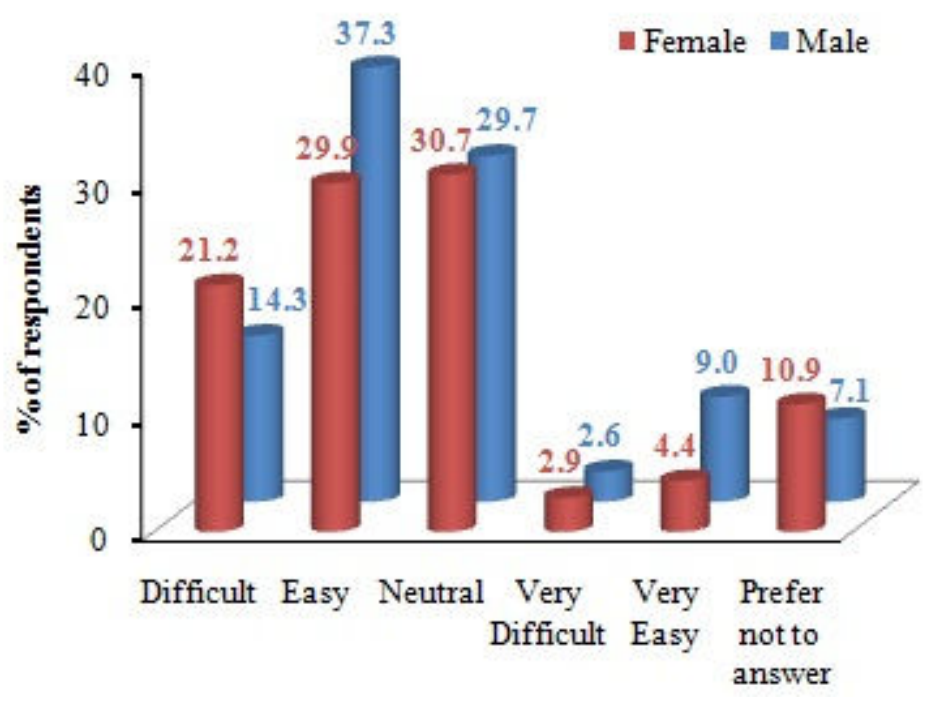

Figure 8: Students' perception of overall education system in U.S. 34\% of female students felt easy, whereas $24 \%$ found difficult. 


\section{Discussions and Recommendations:}

Most of the higher education institutions in U.S. have common strategies to recruit and retain engineering graduate students. Results presented in this study indicate that female and male students have different criterion to choose a school. These factors can be incorporated in current recruitment and retention efforts to increase the number of female graduate engineering students. In most of the questions asked as a part of this survey, female responded differently than male students. As expected, female students generally related their concerns and preferences at personal and direct contacts compared to male students. In response to rank most common concerns/ influential factors before attending graduate school/to choose a school, female students ranked finding a quality academic advisor in top three. For male students, location of university and VISA requirements were more important. 'Correspondence with faculty members or graduate school' was more important for female students compared to male counterparts. Based on responses to 'challenges faced during the graduate studies' and 'helpfulness of different organizations', female students were found to be more satisfied and happy compared to male students. These results match with findings from other publication showing higher retention rates for female students.

Recruitment efforts can be directed based on results found in this paper and diversity of female students can be increased based on responses from students of different countries around the world. Faculty members and administrators can help in implementing policy based on the findings presented here.

\section{Conclusions:}

This paper discusses the preferences, concerns, influential factors and challenges faced by female graduate students based on online survey completed by international graduate students in at U.S. universities. Survey findings can also be used by educational institutions to enhance recruitment and maintain retention of female students in graduate engineering programs. Survey results are presented here with an objective to instigate the process of including the discussed factors in recruitment and retention effort taken by higher educational institutions as well as to provide guidance to policy makers, administrators and faculty members.

This study is focused on certain important aspects like common concerns of graduate international students, influential factors in choosing a school, challenges faced during graduate studies, experience with faculty members, and overall experience of education system in U.S. Responses were discussed for current engineering students based on gender of the respondent. Result findings show that female students have different set of criteria and attitude to choose a school, handling challenges and prioritizing their needs compared to male student population.

\section{Bibliography:}

1. Nerad, M., \& Miller, D., Increasing student retention in graduate and professional programs. In J. Haworth, (Ed.), Assessing graduate and professional education: Current realities, future prospects. New Directions for Institutional Research, 92. San Francisco, CA: Jossey Bass, 61-76, 1996 
2. Zepke, N., \& Leach, L., Integration and adaptation: Approaches to the student retention and achievement puzzle. Active Learning in Higher Education, 6(1), 46-59, 2005

3. Yurtseven, H. O., How does the image of engineering affect student recruitment and retention? A perspective from the USA. Global Journal of Engineering Education 6 (1): 17-23, 2002

4. Linda K. Lau, "Institutional Factors Affecting Student Retention" Education, Vol. 124, 2003

5. Foor, C., Walden, S., and Trytten, D., "I wished I belonged more in this whole engineering group:" achieving individual diversity. Journal of Engineering Education. 96(2): 103-15, 2007.

6. Peterson, D.M., Briggs, P., Dreasher, L., Horner, D.D., \& Nelson, T., Contributions of International Students and Programs to Campus Diversity. New Directions for Student Services 86, 77, 1999

7. Edward Gehringer, "Understanding and relating to your international students", American Society for Engineering Education, 2008

8. Soumya Keshavamurthy, Anurag Srivastava, Adrienne Minerick, and Noel Schulz, "Challenges for international students in a globally changing environment", Proceedings of the 2008 ASEE Annual Conference and Exposition, Pittsburgh, 2008.

9. Soumya K Srivastava, Anurag Srivastava, Adrienne Minerick, and Noel Schulz, "International graduate students' challenges: a survey-based study", Proceedings of the 2009 ASEE Annual Conference and Exposition, 2009

10. Fazil Najafi, Dennis Jet and Nick Safai, "A global model for higher educational institutions to increase the enrollment of minority and international students", Proceedings of the 2008 ASEE Annual Conference and Exposition, Pittsburgh, 2008.

11. J. C. Blickenstaff, "Women and science careers: leaky pipeline or gender filter", Journal of Gender and Education, October 2005, 17(4):369-386

12. A. Langen and H. Dekkers, "Cross-national differences in participating in tertiary science, technology, engineering and mathematics education", Journal of Comparative Education, August 2005, 41(3):329-350

13. P. Roberts and M. Ayre, "Did she jump or was she pushed? A study of women's retention in the engineering workforce", International Journal of Engineering Education, 2002, 18(4): 415-421

14. J. M. Bystydzienski and S. R. Bird, "Removing barriers: women in academic science, technology, engineering, and mathematics", Indian University Press, 2006

15. "Wanted: Women Scientists"; OCED observer no 257, 2006; http://www.oecdobserver.org/news/fullstory.php/aid/2097/Wanted:_Women_scientists.html (accessed on Oct $8^{\text {th }}$ 2009)

16. Margaret Loftus, "Why won't she listen", ASEE Prism, 2007, 17(3)

17. Markert, L. R. (1996). Gender related to success in science and technology. The Journal of Technology Studies, 22(2), 21-29.

18. SG Brainard, L Carlin, "A Longitudinal Study of Undergraduate Women in Engineering \& Science", Frontiers in Education Conference, 1997

19. Steele J., James J.B., Barnett R.C., "Learning in a Man'S World: Examining the Perceptions of Undergraduate Women in Male-Dominated Academic Areas", Psychology of Women Quarterly, Volume 26, Number 1, March 2002 , pp. 46-50(5)

20. Jones, M.G., Howe, A., \& Rua, M.J., Gender differences in students' experiences, interests, and attitudes toward science and scientists. Science Education, 84, 180-192, 2000

21. N.B. Koppel, R.M. Cano, S.B. Heyman, "An attractive engineering option for girls," Frontiers in Education, Annual, vol. 3, pp. F1C2-7, 32nd Annual Frontiers in Education (FIE'02), 2002. November 06November 09

22. Agogino, A. M., \& Hsi, S. "Learning Style Based Innovations to improve Retention of Female Engineering Students in the Synthesis Coalition", Proceedings of the 1995 Frontiers in Education Conference, 1995

23. Janice Cuny, William Aspray Recruitment and retention of women graduate students in computer science and engineering: results of a workshop organized by the computing research association" ACM SIGCSE Bulletin, Volume 34 , Issue 2, Women and Computing, 168 - 174, 2002

24. Felder, R.M., G.N. Felder, M. Mauney, C.E. Hamrin, Jr., and E.J. Dietz, "A Longitudinal Study of Engineering Student Performance and Retention. III. Gender Differences in Student Performance and Attitudes," Journal of Engineering Education, vol. 84, no. 2, 1995, 151-174. 